\title{
miR-224 promotes colorectal cancer cells proliferation via downregulation of $\mathrm{P} 21^{\mathrm{WAF} 1 / \mathrm{CIP} 1}$
}

\author{
XIUMEI ZHANG, XIA ZHANG, CHAO LIU, NING JIA, XINYU LI and JIANYING XIAO \\ Department of Biochemistry and Molecular Biology, Liaoning Medical University, Jinzhou, Liaoning 121000, P.R. China
}

Received April 15, 2013; Accepted November 14, 2013

DOI: $10.3892 / \mathrm{mmr} .2014 .1900$

\begin{abstract}
MicroRNAs (miRNAs) are between 19 and 25 mer non-coding RNAs involved in cancer cell proliferation, apoptosis, stress responses and maintenance of stem cell potency. In the present study, miR-224 was observed to be upregulated in colorectal cancer (CRC) tissue. Overexpression of miR-224 facilitated proliferation of the CRC cell lines, HCT-116 and SW-480. Bioinformatics analysis revealed a putative miR-224 binding site in the 3'-untranslated region of CDKI1A $\left(\mathrm{P} 21^{\mathrm{WAF} 1 / \mathrm{CIPl}}\right)$. Western blot analysis and the luciferase reporter assay proved that miR-224 represses $\mathrm{P} 21^{\mathrm{WAF} 1 / \mathrm{CIP} 1}$ expression and promotes cell cycle $\mathrm{G}_{1} / \mathrm{S}$ transition. These results suggest that the downregulation of miR-224 in CRC is a novel potential therapeutic strategy.
\end{abstract}

\section{Introduction}

Colorectal cancer (CRC) is the fourth most common type of cancer and the third leading cause of cancer-related mortalities in the western world (1). Thus, in recent years, an increasing number of studies have focused on its mechanisms.

MicroRNAs (miRNAs) are endogenous small non-coding RNAs that inhibit gene expression by binding complementary sequences in the 3'-untranslated regions (3'-UTR) of the target mRNAs $(2,3)$. Mounting evidence has shown the important role of miRNAs in regulating various functions, including cell proliferation, apoptosis, differentiation and survival (4). Over the past few decades, it has become clear that miRNA is markedly altered in CRC and that this aberrant miRNA expression is associated with diagnosis and prognosis, as well as the therapeutic outcome of CRC (5-8).

miR-224 is located on the human $\mathrm{X}$-chromosome and a number of studies have demonstrated that miR-224 is

Correspondence to: Dr Xiumei Zhang or Professor Jianying Xiao, Department of Biochemistry and Molecular Biology, Liaoning Medical University, 40 Songpo Road, Jinzhou, Liaoning 121000, P.R. China

E-mail: zhangxiumei9879@sina.com

E-Mail: xiaojianying@lnmu.edu.cn

Key words: colorectal cancer, microRNA, miR-224, P21 ${ }^{\mathrm{WAF} 1 / \mathrm{CIP} 1}$, proliferations upregulated in hepatocellular $(9,10)$, breast (11) and pancreatic cancers (12). More recently, the elevation of miR-224 in hepatocellular carcinoma is through epigenetic mechanisms (10), its overexpression promotes cell proliferation, anti-apoptosis, migration and invasion $(9,13)$. miR-224 has been shown to be involved in transforming growth factor (14) and raf kinase inhibitor protein (RKIP) (11) pathway-mediated tumor growth and metastasis.

Although miR-224 is underexpressed when colon cancer cells are exposed to 5-fluorouracil (15) or in methotrexate-resistant colon cancer cells (16), in the majority of CRCs, miR-224 is upregulated. This has been confirmed by miRNA microarray assay performed by $\mathrm{Fu}$ et al (17) and Wang et al (18). In the current study, miR-224 was observed to be upregulated in 12 CRC tissues compared with corresponding adjacent normal tissues. Overexpression of miR-224 may facilitate the proliferation of CRC cell lines. miR-224 promotes CRC cell line $\mathrm{G}_{1} / \mathrm{S}$ transition and this progress may be mediated by the repression of cyclin-dependent kinase inhibitors-P21 (CDKN1A), which was confirmed as a new target of miR-224 in the study.

\section{Materials and methods}

Patient samples. A total of 12 matched CRC and their corresponding normal mucosal tissues $(>5 \mathrm{~cm}$ laterally from the edge of the cancerous region), were collected from 12 patients undergoing tumor resection in the First Affiliated Hospital of Liaoning Medical University. All the samples were divided into smaller parts, preserved in liquid nitrogen following retrieval and histologically confirmed. The study was approved by the ethics committee of Liaoning Medical University and written informed consent was obtained from all patients.

Cell culture. The human CRC cell lines HCT-116 and SW-480, were purchased from the Cell Bank of Shanghai (Shanghai, China) and were cultured in RPMI-1640 medium supplemented with $10 \%$ fetal calf serum, $100 \mathrm{U} / \mathrm{ml}$ penicillin and $100 \mathrm{U} / \mathrm{ml}$ streptomycin at $37^{\circ} \mathrm{C}$ in a $5 \% \mathrm{CO}_{2}$ incubator.

RNA extraction and quantitative polymerase chain reaction $(q P C R)$. Total RNA was isolated from patient samples or cultured cells using TRIzol reagent (Invitrogen Life Technologies, Carlsbad, CA, USA) and the miRNA was purified with the mirVana miRNA Isolation kit (Ambion, Austin, TX, USA) according to the manufacturer's instructions. A 
stem-loop RT-PCR assay was performed to detect the mature miRNA levels. The reverse transcription primer for miR-224 was: 5'-CTCAACTGGTGTCGTGGAGTCGGCAATTCAG TTGAGAACGGAAC-3' and U6 snRNA: 5'-AACGCTTCAC GAATTTGCGT-3'. The cDNA was then amplified by SYBR $^{\circledR}$ Premix Ex-Taq ${ }^{\mathrm{TM}}$ II (Takara Biotechnology Inc., Dalian, China) using the primers: miR224-forward, 5'-ACAC TCCAGCTGGGCAAGTCACTAGTGGT-3' and reverse, 5'-TGGTGTCGTGGAGTCG-3'; U6-forward, 5'-CTCGCTT CGGCAGCACA-3'and reverse, 5'-AACGCTTCACGAATTT GCGT-3' and P21-forward, 5'-CGATGGAACTTCGACT TTGTCA-3' and reverse, 5'-GCACAAGGGTACAAGACA GTG-3'. PCR was performed using the following conditions: $95^{\circ} \mathrm{C}$ for $1 \mathrm{~min}$, followed by 46 cycles of $95^{\circ} \mathrm{C}$ for $15 \mathrm{sec}$ and $60^{\circ} \mathrm{C}$ for $40 \mathrm{sec}$.

MTT assay. Logarithmically growing HCT-116 and SW-480 cells were seeded in 96 -well plates $\left(5 \times 10^{3}\right.$ cells $/ 100 \mu 1$ medium/well). The culture medium was replaced after $24 \mathrm{~h}$ with fresh medium and the miR-224 mimics, miR-224 inhibitor and negative control $(100 \mathrm{nM})$ were transfected (GenePharma, Shanghai, China) with Lipofetamine 2000 (Invitrogen Life Technologies). Cells were incubated for $4 \mathrm{~h}$ in the presence of $20 \mu \mathrm{l}$ MTT solution (5 g/l; Sigma-Aldrich, St. Louis, MO, USA) and following $36 \mathrm{~h}$ transfection, the supernatants were carefully discarded and DMSO (100 $\mu \mathrm{l} /$ well) was added. The spectrophotometric absorbance of each sample was measured at $490 \mathrm{~nm}$. The experiments were repeated three times and the average results were calculated.

Cell cycle analysis. HCT-116 and SW-480 cells were transfected with miR-224 mimics, inhibitor or negative control miRNA. Following $36 \mathrm{~h}$ culture, the cells were collected, washed with phosphate-buffered saline and fixed with $70 \%$ ice-cold ethanol at $4^{\circ} \mathrm{C}$ overnight. The fixed cells were washed twice and resuspended in $300 \mu \mathrm{l}$ stain buffer $(50 \mathrm{mg} / \mathrm{ml} \mathrm{PI}$, $1 \mathrm{mg} / \mathrm{ml}$ Rnase A, $0.2 \%$ Tween-20) for $30 \mathrm{~min}$ at $37^{\circ} \mathrm{C}$ in the dark prior to flow cytometry (Beckman Coulter, Inc., Brea, CA, USA).

Target validation with luciferase reporter. The reporter constructs containing 3 '-UTR P21 ${ }^{\mathrm{WAF} / \mathrm{CIP1}}$ were cloned into the pMIR-REPORT $^{\mathrm{TM}}$ vector (Ambion) using PCR-generated fragments. The mutant was constructed with QuikChange XL Site Directed Mutagenesis kit (Stratagene, La Jolla, CA, USA). The primers used were: P21-UTR-wt-forward,5'-TCACGCGGT GAGCACAGCCTAGGGCTG and reverse, GTACTAGTGT AAAGTCACTAAGAATCATTTATTGAGC; P21-UTR-mtforward, TCACGCGTGTGAGCACAGCCTAGGGCTG and P21-UTR-mt-reverse, GTACTAGTGTAAACAGTGATAGAA TCATTTATTGAGC. HCT-116 and SW-480 cells were seeded in a 24 -well plate $\left(1 \times 10^{5}\right.$ cells/well) and were co-transfected $24 \mathrm{~h}$ later with $400 \mathrm{ng}$ of the reporter vector and $10 \mathrm{ng}$ pMIR-REPORT- $\beta$ gal control plasmid, which was used to normalize transfection efficiency and $100 \mathrm{nM}$ miR-224 mimics, inhibitor or negative control miRNA using Lipofectamine. The cells were harvested for luciferase assays $36 \mathrm{~h}$ after transfection. Reporter gene assays were performed in triplicate using Luciferase Assays kits (Promega Corporation, Madison, WI, USA). The experiment was repeated three times.

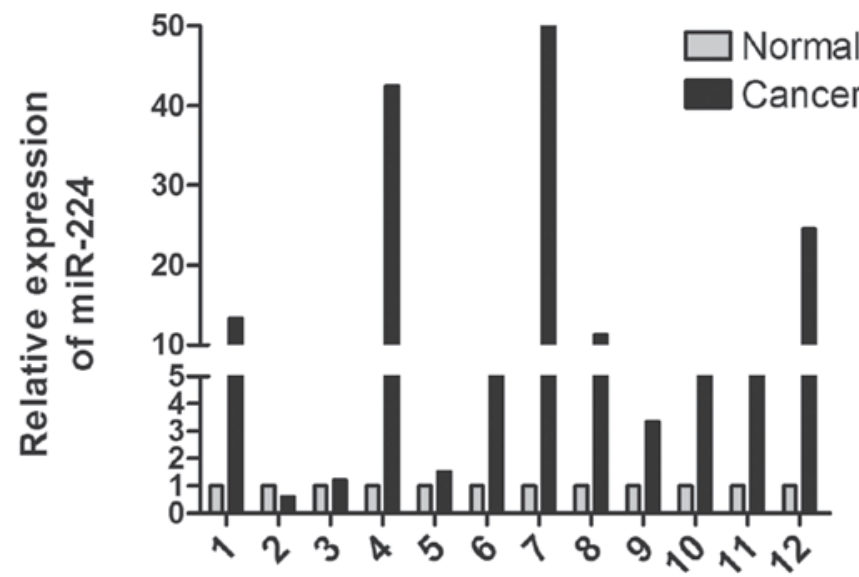

Figure 1. The relative expression of miR-224 in 12 pairs of CRC and the corresponding distal matched normal tissues by using quantitative polymerase chain reaction. The expression levels of miR-224 were normalized against the U6. CRC, colorectal cancer.

Western blot analysis. For western blot analysis, protein extracts were prepared by resuspending cell pellets in $1 \%$ NP-40 (Sigma-Aldrich) lysis buffer containing $50 \mathrm{mM}$ Tris- $\mathrm{HCl}$ (pH 8.0), $150 \mathrm{mM} \mathrm{NaCl}, 1 \mathrm{mM}$ EDTA, $5 \mathrm{mM}$ NaF, $2 \mathrm{mM}$ PMSF, $1 \mathrm{mM}$ Na-orthovanadate, and $10 \mu \mathrm{g} / \mathrm{ml}$ leupeptin and aprotinin, respectively. The proteins were separated by $10 \%$ SDS-PAGE and transferred to polyvinylidene difluoride membranes (Amersham, Piscataway, NJ, USA ). The membranes were blocked with 5\% milk powder in TBS and $0.1 \%$ Tween-20 for $1 \mathrm{~h}$ and then incubated overnight with a P21 antibody (Cell Signaling Technology, Inc., Danvers, MA, USA; 1:1,000) and GAPDH antibody (Kangchen Bio-tech, Inc., Shanghai, China; 1:10,000).

Statistical analysis. Data are expressed as mean \pm SD or median values. The expression of miR-224 in the CRC samples and adjacent non-tumor tissues were compared using a paired t-test. Continuous variables were compared by an independent two-sample t-test for two groups. Statistical analysis was performed using IBM SPASS Statistics V17.0 (IBM Corporation, Armonk, NY, USA). $\mathrm{P}<0.05$ was considered to indicate a statistically significant difference.

\section{Results}

$m i R-224$ is upregulated in $C R C$. miR-224 is an oncogene that is overexpressed in a number of tumor tissues $(11,12,19-21)$. To detect the expression of miR-224 in CRC, 12 pairs of matched human CRC tissues and the adjacent paracancerous tissue were analyzed by qPCR (Fig. 1A). The data indicate that miR-224 is markedly upregulated in CRC tissue (paired t-test, $\mathrm{P}=0.0227$ ).

miR-224 overexpression promotes CRC cell proliferation. To determine the impact of miR-224 on CRC cells, HCT-116 and SW-480 cell lines were transfected with miR-224 mimics and inhibitors and the proliferation of CRC cells was detected using MTT. As shown in Fig. 2A, the results of the MTT assay revealed that overexpression of miR-224 significantly increased 
A

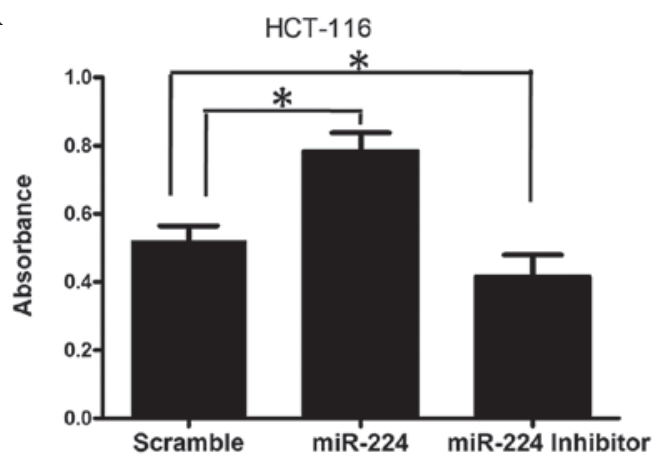

B
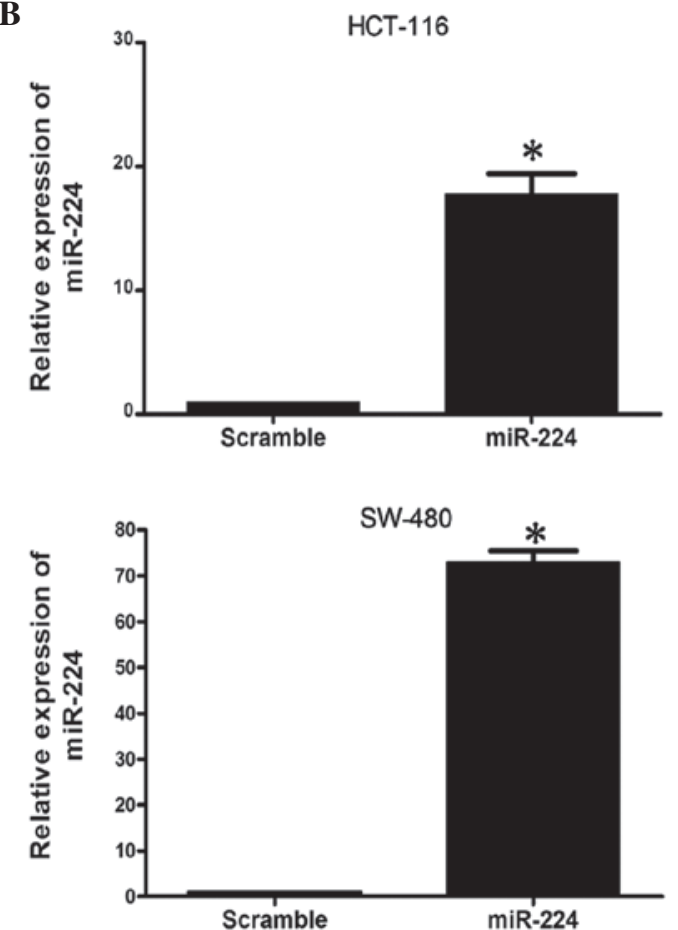

SW -480
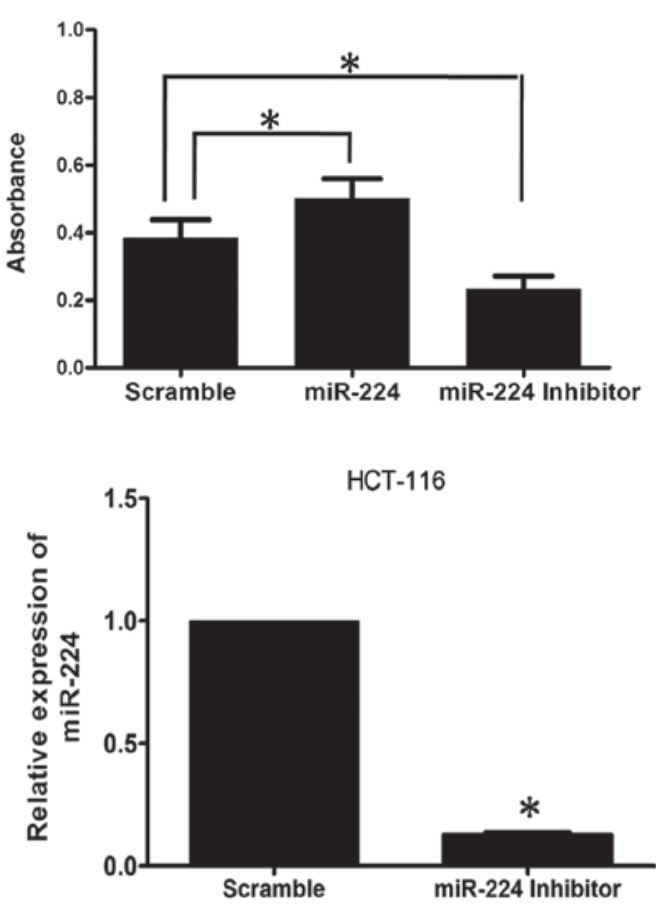

SW-480

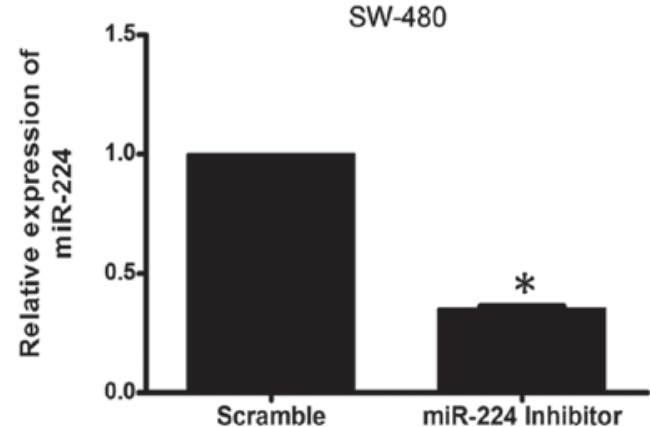

Figure 2. The effect of miR-224 on CRC cell growth in vitro. (A) Cell proliferation assay (MTT). (B) The expression of miR-224 was detected by quantitative-polymerase chain reaction following cell transfection with miRNA Scramble, miR-224 mimics and miR-224 inhibitors for $36 \mathrm{~h}$ post-transfection ("P $<0.05$ vs. miRNA Scramble). CRC, colorectal cancer.

cell growth in the two CRC cell lines. When miR-224 was inhibited by transfection with miR-224 inhibitors, this function was reversed. The transfection efficiency was confirmed by qPCR (Fig. 2B).

miR-224 directly targets $P 21^{\text {WAFI/CIPI }}$ at the translational level. Considering the effect of miR-224 on CRC cell growth, possible targets, which are associated with cell proliferation were selected following bioinformatics analysis using microRNA.org and targetscan. CDKN1A, also known as $\mathrm{P} 21^{\mathrm{WAF} 1 / \mathrm{CIP} 1}$, was observed to have a potential miR-224 binding site (Fig. 3A). To validate the miRNA-target interactions, the expression of P21 was evaluated in HCT-116 and SW-480 cells transfected with miR-224 mimics, miR-224 inhibitor or negative control. As shown in Fig. 3B, the protein level of P21 was downregulated following transfection with miR-224 and upregulated when miR-224 was blocked, while P21 mRNA exhibited no significant change. To confirm whether P21 is regulated by miR-224 through direct binding to its 3'-UTR, a human P21 3'-UTR fragment containing wild-type (wt-UTR) or mutant (mt-UTR) was cloned into the pMIR-REPORT vector (Fig. 3C). CRC cell lines were then co-transfected with wt or mt UTR vector. As shown in Fig. 3D, the relative luciferase activity of the reporter containing wt-UTR was significantly suppressed following miR-224 transfection. However, variations were not observed in the luciferase activity of cells co-transfected with mt-UTR and miR-224. The results therefore suggest that P21 is a target gene of miR-224.

miR-224 regulates the cell cycle of CRC cells. Due to the regulation of $\mathrm{P} 21$, the role of miR-224 in the regulation of cell cycle in CRC cell lines was assessed. A flow cytometric analysis was performed following transfection with miR-224 mimics, inhibitors or negative control. The analysis results revealed that CRC cells overexpressing miR-224 exhibited an increase in the $\mathrm{S}$-phase population and a decrease of $\mathrm{G}_{1}$ population, while the group treated with the miR-224 inhibitor exhibited converse results compared with the negative control (Fig. 4). 
A

3' uugccUUGGUGAUCACUGAAC 5' hsa-miR-224

$:$ | : : : | | | | | | | | |

1511: 3' uaaauGAUU CUUAGUGACUUu 3' CDKN1A

B
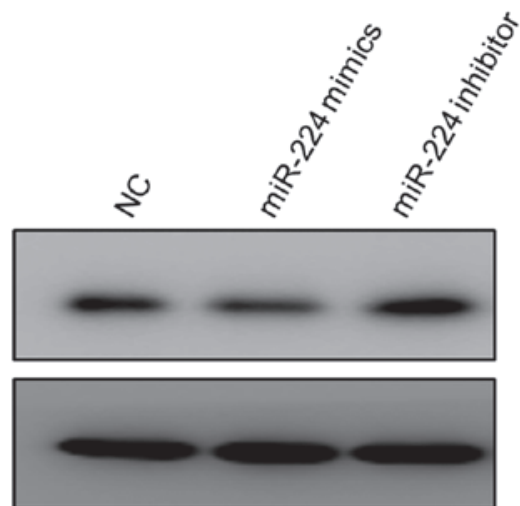

SW-480
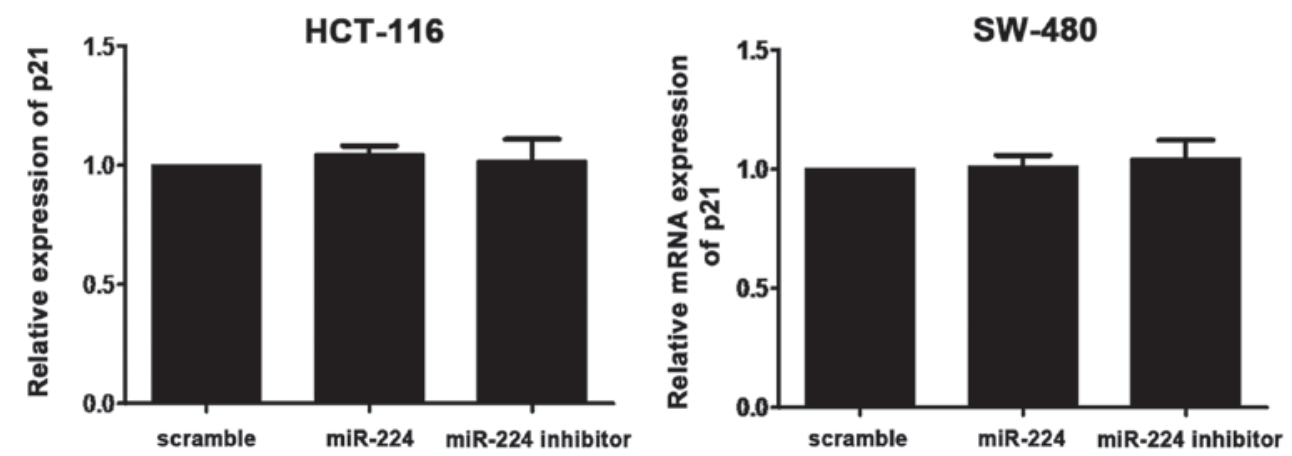

C

miR-224: 3' uugccUUGGUGAUCACUGAAC 5'

$:|:: \quad:|||||||||$

P21-UTR-mt: 5' uaaauGAUU CUUAGUGACUUu 3'

P21-UTR-wt: 5' uaaauGAUU CUAUCACUGUUu 3'

D

HCT-116
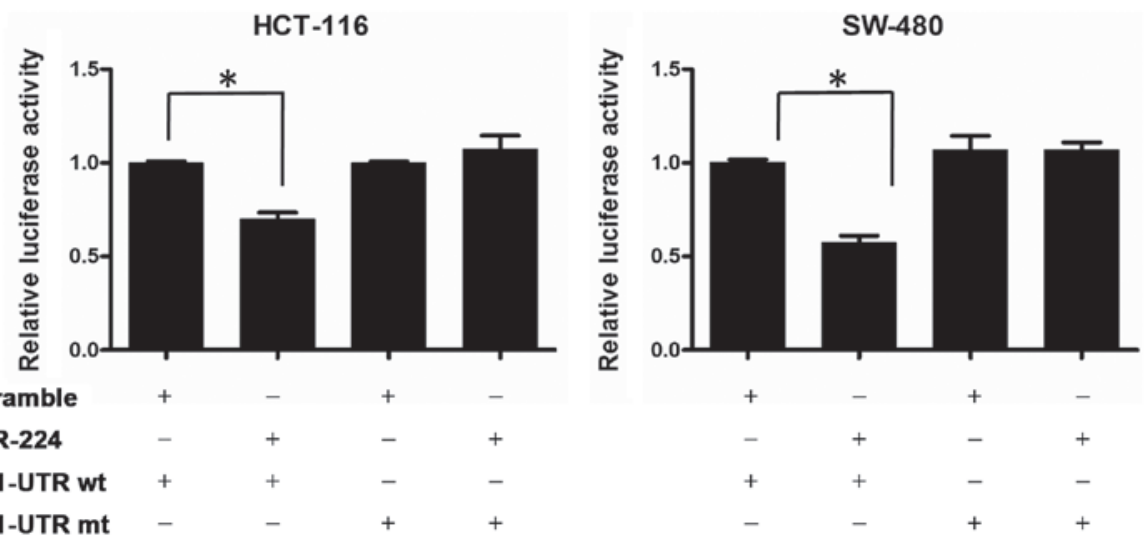

Figure 3. P21 is a direct target of miR-224 in CRC cells. (A) P21 has a putative binding site of miR-224 as predicted by microRNA.org. (B) Western blot analysis and quantitative-polymerase chain reaction assay results of the endogenous P21 protein and mRNA levels in CRC cell lines following transfection with miR-224 mimics, inhibitors or negative control. (C) The wild-type and mutated-type of P21 3'-UTR were cloned into pMIR-REPORT vector (mutated sites are underlined). (D) Analysis of luciferase activity. The UTR-wt or UTR-mt reporter plasmids were co-transfected into HCT-116 and SW-480 cells. Luciferase activity was assayed $36 \mathrm{~h}$ following transfection. Data are the means of three independent experiments, bars, mean $\pm \mathrm{SD}$. ("P $<0.05 \mathrm{vs}$. control). CRC, colorectal cancer; UTR, untranslated region.

\section{Discussion}

Accumulating evidence has demonstrated an important role of miRNAs in tumorigenesis and tumor progression, diagnosis and treatment (22). Despite the identification of a number of miRNA targets involved in human tumors, the majority of mechanisms remain unclear. The expression of miR-224 is abnormal in several types of cancer, and is associated with 
A
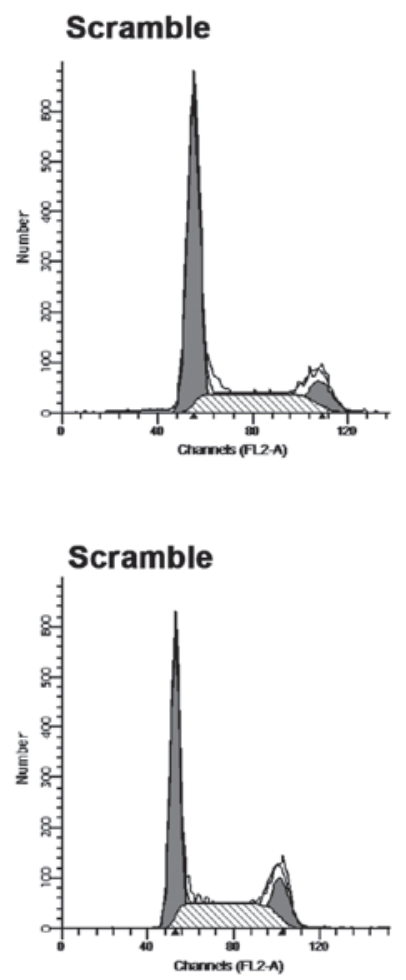

HCT-116

miR-224

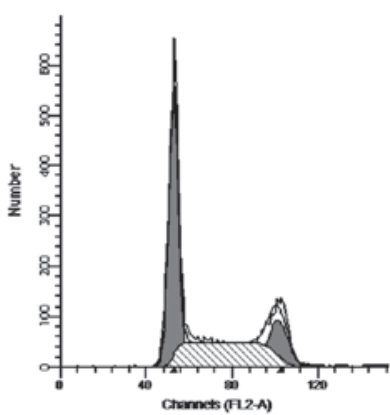

SW-480

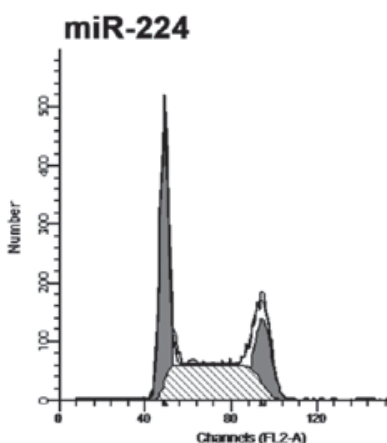

\section{miR-224 inhibitor}

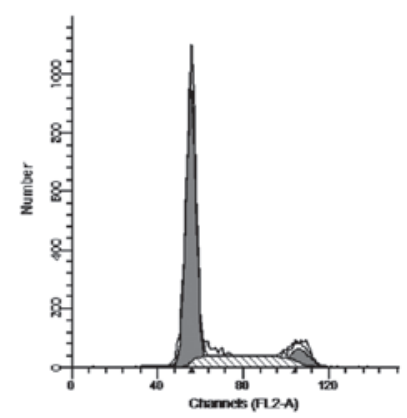

miR-224 inhibitor

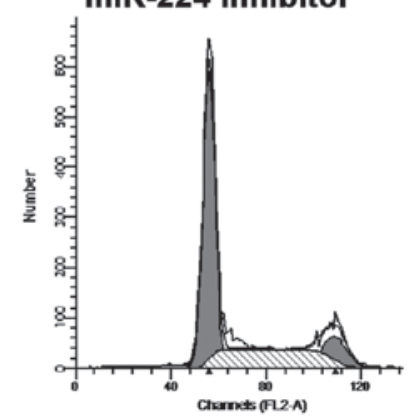

B
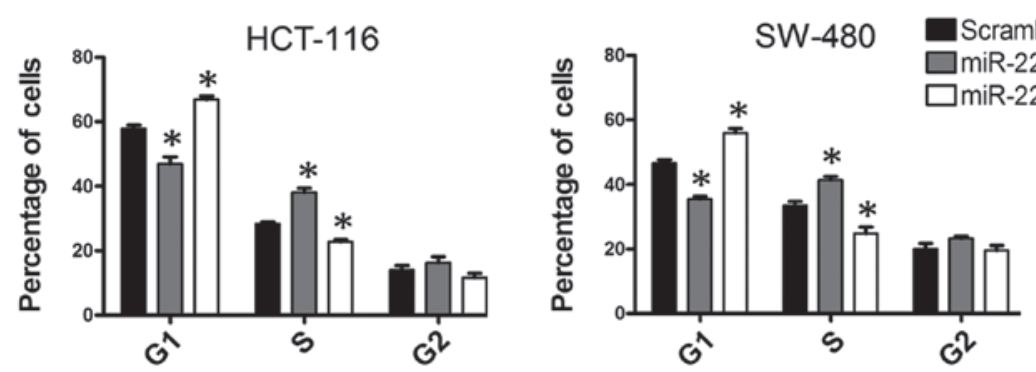

Figure 4. miR-224 affects cell cycle progression. Cell cycle analysis of miR-224 at $36 \mathrm{~h}$ following transfection showed that the cells transfected with miR-224 had a decreased population of G1 and an increase in the S-phase compared with the negative control. However, when the miR-224 is blocked, this phenomenon is reversed ( $\mathrm{P}<0.05$ vs. miRNA scramble).

histone acetylation (10) and inflammation (19). Although miR-224 represses hepatocellular and breast cancer metastasis by targeting RKIP $(11,23)$, its mechanism on tumor growth remains to be clarified.

Growth and proliferation of cancer cells is key to tumor progression. miRNAs, including miR-21, miR-223 and miR-145 may regulate cancer cell proliferation by repressing the translation of the targets (24-26).

The cell cycle consists of the G1, S, G2 and M phases. Cyclins and cyclin-dependent kinases (CDKs) are the two most important regulatory molecules in the cell cycle (27). Different cyclin-CDK complexes control cell cycle progression by organized synthesis and degradation. Cell cycle progression may be prevented by two families of the inhibitor: CDK interacting protein/kinase inhibitory protein (cip/kip) and the inhibitor of kinase 4/alternative reading frame. A previous study revealed that dysregulation of the cell cycle leads to tumor formation (28).

P21 (CDKN1A), together with P27 (CDKN1B) and P57 (CDKN1C), are the members of cip/kip. The decreased expression of P21 is associated with CRC proliferation and prognosis (29-31) and is involved in numerous pathways. Furthermore, this function is associated with the expression of the P53 status (32-34). As a key molecule in the progression of the cell cycle, $\mathrm{P} 21$ negatively regulates cell cycle and transient expression in tumor cells, resulting in the inhibition of cell proliferation $(35,36)$. However, despite its considerable role in tumor progression, when present in low levels, P21 does not function efficiently.

The current data demonstrate that miR-224 regulates CRC cell growth by targeting P21 $1^{\mathrm{WAF} 1 / \mathrm{CIP} 1}$. This hypothesis is confirmed by western blotting and luciferase assays. Overexpression of miR-224 decreased the P21 protein level and the luciferase activity of P21 3'-UTR. The result was confirmed when the miR-224-binding site was mutated and the luciferase activity exhibited no specific change. The results of the study demonstrate that a decrease of P21 in cancer may be caused by overexpression of miR-224. This hypothesis was confirmed by the flow cytometric analysis.

In conclusion, the results reveal the role of miR-224 in CRC. The expression levels of miR-224 were significantly 
upregulated in CRC tissue. It promotes cell proliferation and the cell cycle phase transition from $\mathrm{G}_{1}$ to $\mathrm{S}$ by targeting P21. Therefore, miR-224 may be a novel therapeutic target of CRC.

\section{Acknowledgements}

This work was supported by the Natural Science Foundation of Liaoning Province (no. 2013022068) and National Natural Science Foundation of China (no. 81270696). The author thanks Dr J Khan for generously providing the pMIR-REPORT vector.

\section{References}

1. Ohtani H, Tamamori Y, Arimoto Y, Nishiguchi Y, Maeda K and Hirakawa K: A meta-analysis of the short- and long-term results of randomized controlled trials that compared laparoscopy-assisted and conventional open surgery for colorectal cancer. J Cancer 2: 425-434, 2011.

2. Ambros V: The functions of animal microRNAs. Nature 431: 350-355, 2004

3. Lytle JR, Yario TA and Steitz JA: Target mRNAs are repressed as efficiently by microRNA-binding sites in the 5' UTR as in the 3' UTR. Proc Natl Acad Sci USA 104: 9667-9672, 2007.

4. Friedman RC, Farh KK, Burge CB and Bartel DP: Most mammalian mRNAs are conserved targets of microRNAs. Genome Res 19: 92-105, 2009.

5. Yamashita S, Yamamoto H, Mimori K, et al: MicroRNA-372 is associated with poor prognosis in colorectal cancer. Oncology 82: 205-212, 2012

6. Rossi S, Di Narzo AF, Mestdagh P, et al: microRNAs in colon cancer: a roadmap for discovery. FEBS Lett 586: 3000-3007, 2012.

7. Rawson JB and Bapat B: Epigenetic biomarkers in colorectal cancer diagnostics. Expert Rev Mol Diagn 12: 499-509, 2012

8. Ahmed FE, Amed NC, Vos PW, et al: Diagnostic microRNA markers to screen for sporadic human colon cancer in blood. Cancer Genomics Proteomics 9: 179-192, 2012.

9. Wang Y, Lee AT, Ma JZ, et al: Profiling microRNA expression in hepatocellular carcinoma reveals microRNA-224 up-regulation and apoptosis inhibitor-5 as a microRNA-224-specific target. J Biol Chem 283: 13205-13215, 2008.

10. Wang Y, Toh HC, Chow P, et al: MicroRNA-224 is up-regulated in hepatocellular carcinoma through epigenetic mechanisms. FASEB J 26: 3032-3041, 2012.

11. Huang L, Dai T, Lin X, et al: MicroRNA-224 targets RKIP to control cell invasion and expression of metastasis genes in human breast cancer cells. Biochem Biophys Res Commun 425: 127-133, 2012

12. Mees ST, Mardin WA, Sielker S, et al: Involvement of CD40 targeting miR-224 and miR-486 on the progression of pancreatic ductal adenocarcinomas. Ann Surg Oncol 16: 2339-2350, 2009.

13. Zhang Y, Takahashi S, Tasaka A, Yoshima T, Ochi H and Chayama K: Involvement of microRNA-224 in cell proliferation, migration, invasion and anti-apoptosis in hepatocellular carcinoma. J Gastroenterol Hepatol 28: 565-575, 2013.

14. Yao G, Yin M, Lian J, et al: MicroRNA-224 is involved in transforming growth factor-beta-mediated mouse granulosa cell proliferation and granulosa cell function by targeting Smad4. Mol Endocrinol 24: 540-551, 2010.

15. Rossi L, Bonmassar E and Faraoni I: Modification of miR gene expression pattern in human colon cancer cells following exposure to 5-fluorouracil in vitro. Pharmacol Res 56: 248-253, 2007.
16. Mencia N, Selga E, Noe V and Ciudad CJ: Underexpression of miR-224 in methotrexate resistant human colon cancer cells. Biochem Pharmacol 82: 1572-1582, 2011.

17. Fu J, Tang W, Du P, et al: Identifying microRNA-mRNA regulatory network in colorectal cancer by a combination of expression profile and bioinformatics analysis. BMC Syst Biol 6: 68, 2012.

18. Wang YX, Zhang XY, Zhang BF, Yang CQ, Chen XM and Gao HJ: Initial study of microRNA expression profiles of colonic cancer without lymph node metastasis. J Dig Dis 11: 50-54, 2010.

19. Scisciani C, Vossio S, Guerrieri F, et al: Transcriptional regulation of miR-224 upregulated in human HCCs by NFאB inflammatory pathways. J Hepatol 56: 855-861, 2012.

20. Wotschofsky Z, Busch J, Jung M, et al: Diagnostic and prognostic potential of differentially expressed miRNAs between metastatic and non-metastatic renal cell carcinoma at the time of nephrectomy. Clin Chim Acta 416: 5-10, 2013.

21. Liu ZR, Chen XW, Qiao XH, Wang R and Xiang Z: Detection of miR-122a and miR-224 expression in hepatocellular carcinoma by real-time fluorescence quantitative RT-PCR. Nan Fang Yi Ke Da Xue Xue Bao 29: 751-753, 2009 (In Chinese).

22. Lu J, Getz G, Miska EA, et al: MicroRNA expression profiles classify human cancers. Nature 435: 834-838, 2005.

23. Poma P, Labbozzetta M, Vivona N, Porcasi R, D'Alessandro N and Notarbartolo M: Analysis of possible mechanisms accounting for raf-1 kinase inhibitor protein downregulation in hepatocellular carcinoma. OMICS 16: 579-588, 2012.

24. Wu L, Li H, Jia CY, et al: MicroRNA-223 regulates FOXO1 expression and cell proliferation. FEBS Lett 586: 1038-1043, 2012.

25. Zhang J, Xiao Z, Lai D, et al: miR-21, miR-17 and miR-19a induced by phosphatase of regenerating liver-3 promote the proliferation and metastasis of colon cancer. Br J Cancer 107: 352-359, 2012.

26. Xu Q, Liu LZ, Qian X, et al: MiR-145 directly targets p70S6K1 in cancer cells to inhibit tumor growth and angiogenesis. Nucleic Acids Res 40: 761-774, 2011.

27. Nigg EA: Cyclin-dependent protein kinases: key regulators of the eukaryotic cell cycle. Bioessays 17: 471-480, 1995.

28. Zucca E and Nigg EA: Cell cycle regulation and the function of cancer genes. Ann Oncol 6: 975-978, 1995.

29. Wang L, Cao XX, Chen Q, Zhu TF, Zhu HG and Zheng L: DIXDC1 targets $\mathrm{p} 21$ and cyclin D1 via PI3K pathway activation to promote colon cancer cell proliferation. Cancer Sci 100: 1801-1808, 2009

30. Mitomi H, Ohkura Y, Fukui N, et al: P21WAF1/CIP1 expression in colorectal carcinomas is related to Kras mutations and prognosis. Eur J Gastroenterol Hepatol 19: 883-889, 2007.

31. Kim JA, Park KS, Kim HI, et al: Troglitazone activates p21Cip/WAF1 through the ERK pathway in HCT15 human colorectal cancer cells. Cancer Lett 179: 185-195, 2002.

32. Pasz-Walczak G and Kordek R: Comparative evaluation of the expression of cell cycle regulating proteins: cyclin D1, P53 and P21 (WAF1) in colorectal cancer. Pol J Pathol 51: 63-69, 2000.

33. Pasz-Walczak G, Kordek R and Faflik M: P21 (WAF1) expression in colorectal cancer: correlation with P53 and cyclin D1 expression, clinicopathological parameters and prognosis. Pathol Res Pract 197: 683-689, 2001.

34. Noske A, Lipka S, Budczies J, et al: Combination of p53 expression and $\mathrm{p} 21$ loss has an independent prognostic impact on sporadic colorectal cancer. Oncol Rep 22: 3-9, 2009.

35. Park KS, Ahn Y, Kim JA, Yun MS, Seong BL and Choi KY: Extracellular zinc stimulates ERK-dependent activation of $\mathrm{p} 21^{\mathrm{Cip} / \mathrm{WAF} 1}$ and inhibits proliferation of colorectal cancer cells. $\mathrm{Br}$ J Pharmacol 137: 597-607, 2002.

36. Al-Maghrabi J, Al-Ahwal M, Buhmeida A, et al: Expression of cell cycle regulators $\mathrm{p} 21$ and $\mathrm{p} 27$ as predictors of disease outcome in colorectal carcinoma. J Gastrointest Cancer 43: 279-287, 2011. 